\title{
Possible Role of Adenosine in the Macula Densa Mechanism of Renin Release in Rabbits
}

Sadayoshi Itoh, Oscar A. Carretero, and Robert D. Murray

Hypertension Research Division, Henry Ford Hospital, Detroit, Michigan 48202

\begin{abstract}
This study was designed to examine: (a) the effects of adenosine and its analogues on renin release in the absence of tubules, glomeruli, and macula densa, and (b) whether adenosine may be involved in a macula densa-mediated renin release mechanism. Rabbit afferent arterioles (Af) alone and afferent arterioles with macula densa attached (Af + MD) were microdissected and incubated for two consecutive 30 -min periods. Hourly renin release rate from a single arteriole (or an arteriole with macula densa) was calculated and expressed as $\mathrm{ng} A \mathrm{AI} \cdot \mathrm{h}^{-1} \cdot \mathrm{Af}^{-1}$ (or Af $\left.+\mathrm{MD}^{-1}\right) / \mathrm{h}$ (where $\mathrm{AI}$ is angiotensin $\mathrm{I}$ ). Basal renin release rate from Af was $0.69 \pm 0.09 \mathrm{ng} \mathrm{AI} \cdot \mathrm{h}^{-1} \cdot \mathrm{Af}^{-1} / \mathrm{h}(\overline{\mathbf{x}} \pm \mathrm{SEM}, n=16)$ and remained stable for $60 \mathrm{~min}$. Basal renin release rate from Af + MD was $0.20 \pm 0.04 \mathrm{ng} \mathrm{AI} \cdot \mathrm{h}^{-1} \cdot \mathrm{Af}+\mathrm{MD}^{-1} / \mathrm{h}(n=6)$, which was significantly lower $(P<0.0025)$ than that from Af. When adenosine $(0.1 \mu \mathrm{M})$ was added to $A f$, renin release decreased from $0.72 \pm 0.16$ to $0.24 \pm 0.04 \mathrm{ng} \mathrm{AI} \cdot \mathrm{h}^{-1} \cdot \mathrm{Af}^{-1} / \mathrm{h}(P$ $<0.025 ; n=9$ ). However, when adenosine was added to Af $+\mathrm{MD}$, no significant change in renin release was observed. $N^{6}$ cyclohexyl adenosine (an $A_{1}$ adenosine receptor agonist) at 0.1 $\mu M$ decreased renin release from $A f$ from $0.69 \pm 0.14$ to $0.39 \pm 0.12 \mathrm{ng} \mathrm{AI} \cdot \mathrm{h}^{-1} \cdot \mathrm{Af}^{-1} / \mathrm{h}(n=5, P<0.05)$. However, $5^{\prime}-$ $\mathrm{N}$-ethylcarboxamide adenosine (an $\mathrm{A}_{2}$ adenosine receptor agonist) either at $0.1 \mu \mathrm{M}$ or at $10 \mu \mathrm{M}$ had no effect. Theophylline, at a concentration $(10 \mu \mathrm{M})$ that does not block phosphodiesterase but does block adenosine receptors, increased renin release from Af + MD from $0.21 \pm 0.03$ to $0.46 \pm 0.08 \mathrm{ng} \mathrm{AI} \cdot \mathrm{h}^{-1} \cdot \mathrm{Af}+\mathrm{MD}^{-1} /$ h $(P<0.05 ; n=8)$. The results are consistent with the hypotheses that adenosine decreases renin release via the activation of $A_{1}$ adenosine receptors, and that adenosine may be an inhibitory signal from the macula densa to juxtaglomerular cells.
\end{abstract}

\section{Introduction}

It has been shown that intrarenal infusions of adenosine decrease renin release in sodium-depleted animals (1-3), and it has been suggested that endogenous adenosine may be a regulator of renin release (1). However, the mechanism by which adenosine inhibits renin release is not well understood. In addition to inhibiting renin release, adenosine has been shown to induce changes in renal hemodynamics (1-4), sodium excretion (1-3), and sympathetic nervous activity (5). Therefore, the inhibitory action of adenosine on renin release could be secondary to these changes.

Address correspondence to Dr. Carretero, Hypertension Research Division, Henry Ford Hospital, 2799 W. Grant Blvd., Detroit, MI 48202. 1985.

Received for publication 29 January 1985 and in revised form 3 June

J. Clin. Invest.

(c) The American Society for Clinical Investigation, Inc.

$0021-9738 / 85 / 10 / 1412 / 06 \$ 1.00$

Volume 76, October 1985, 1412-1417
On the other hand, studies in renal cortical slices (6) have indicated that adenosine directly inhibits renin release.

Increasing the sodium load to the kidney is known to decrease renin release, possibly through a tubular mechanism involving the macula densa segment of the nephron (7). In addition, it has been reported that the infusion of hypertonic saline into the thoracic aorta elevates renal tissue levels of adenosine (8). Based on evidence such as this, it has been proposed that increased sodium chloride transport at the macula densa results in increased adenosine formation; these increased levels of adenosine then inhibit renin secretion from juxtaglomerular cells $(9,10)$.

The present study was designed first to examine the direct effect of adenosine on renin release, and second to examine the possible role of endogenous adenosine in a macula densa mechanism of renin release. For these purposés, we microdissected afferent arterioles alone (11) and afferent arterioles with macula densa attached (12), and incubated the structures in vitro. Using these two preparations, we studied the effects on renin release of adenosine, selective adenosine receptor agonists, and theophylline, a competitive antagonist of adenosine.

\section{Methods}

The following materials were obtained commercially: Medium 199 was obtained from Gibco Laboratories (Grand Island, NY); bovine serum albumin (BSA), from Schwartz/Mann (Div. Becton Dickinson Immunodiagnostics, Orangeburg, NY); sodium heparin $(1,000 \mathrm{U} / \mathrm{ml})$, from Elkins-Sinn, Inc. (Cherry Hill, NJ); sodium pentobarbital (Nembutal, $50 \mathrm{mg} / \mathrm{ml}$ ), from Abbott Laboratories (Irving, TX); adenosine and theophylline, from Sigma Chemical Co. (St. Louis, MO); and $N^{6}$-cyclohexyladenosine, from Biochem-Behring Corp. (La Jolla, CA).

5 - $N$-ethylcarboxamide adenosine was kindly supplied by Dr. James Bristol of Warner Lambert Co., Ann Arbor, MI.

Isolation and incubation procedures for afferent arterioles alone and for afferent arterioles with macula densa attached

The methods for the isolation and incubation of afferent arterioles and afferent arterioles with macula densa attached have been described previously $(11,12)$. Briefly, young male New Zealand White rabbits (1.5$2.5 \mathrm{~kg}$ ) maintained on a low sodium diet containing $0.48 \%$ sodium chloride (Ralston Purina Co., St. Louis, MI) and tap water ad lib. were anesthetized with sodium pentobarbital $(40 \mathrm{mg} / \mathrm{kg}$, i.v.) and given an intravenous injection of heparin. The left kidney was perfused in situ with cold, oxygenated $\left(95 \% \mathrm{O}_{2}\right.$ and $\left.5 \% \mathrm{CO}_{2}\right)$ Medium 199 containing $0.1 \%$ BSA. The kidney was then removed and sliced along the corticomedullary axis. Slices were placed in ice-cold Medium 199 and microdissected at $4^{\circ} \mathrm{C}$ under a stereomicroscope at magnifications up to $100 \times$.

The afferent arterioles were severed from interlobular arteries and glomeruli using hypodermic needles (26-30 gauge). Care was taken to avoid the distortion of arterioles or the disruption of vascular poles. During the microdissection of arterioles with macula densa attached, the thick ascending limb of the loop of Henle and the distal convoluted tubule were each cut off at a point $<50 \mu \mathrm{m}$ from the macula densa.

Fig. 1 shows an electron microscopic photograph of one section of a microdissected afferent arteriole with the macula densa attached. 


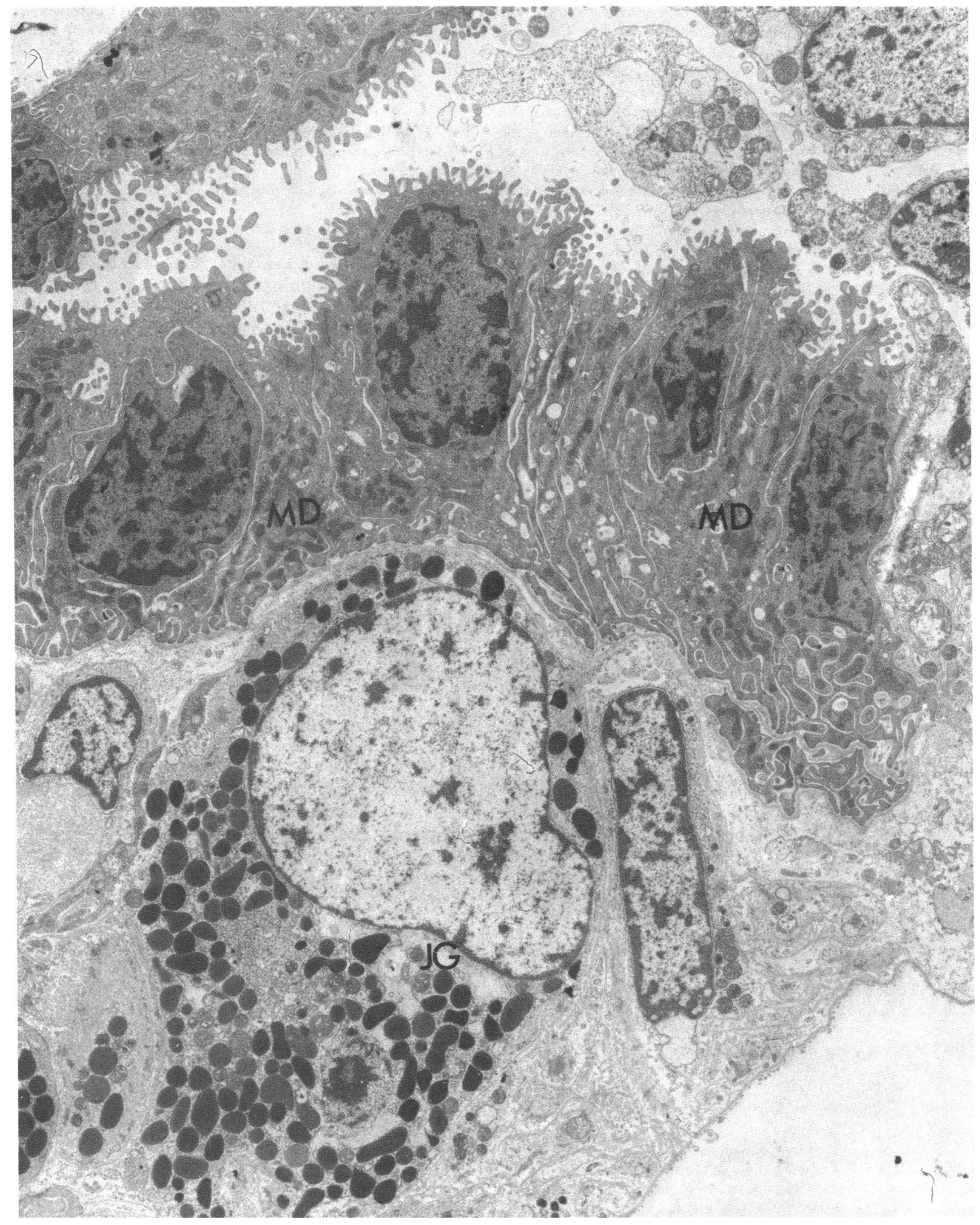

Figure 1. Electron micrograph of microdissected structure after $1 \mathrm{~h}$ of incubation with Medium 199. Micrograph shows macula densa (MD) cells and a juxtaglomerular (JG) cell with renin granules. Magnification, $\times 8,700$. 
Approximately five afferent arterioles and afferent arterioles with macula densa attached were microdissected from the outer half of the cortex in $90 \mathrm{~min}$. The microdissected structures in each group were transferred into a small plastic ladle that had a nylon mesh bottom ( 54 $\mu \mathrm{m}$; Tetko, Inc., Elmsford, NY). The ladles with afferent arterioles or afferent arterioles with macula densa attached were preincubated in 7 $\mathrm{ml}$ of oxygenated Medium $199+0.1 \%$ BSA for $35 \mathrm{~min}$. After preincubation, each ladle was rinsed, blotted, and transferred into a small plastic microtube containing $100 \mu$ l of oxygenated Medium $199+0.1 \%$ BSA. The gas layer above the incubation medium was replaced with $95 \% \mathrm{O}_{2}+5 \% \mathrm{CO}_{2}$, and the microtubes were covered tightly. The microdissected structures were incubated for $30 \mathrm{~min}$ and then the ladle was transferred to fresh medium for another 30 -min incubation period. Incubation medium left in the microtube was frozen $\left(-20^{\circ} \mathrm{C}\right)$ until the renin assay was performed. After serial incubations were completed, it was confirmed microscopically that all microdissected structures remained in the ladle. Microdissected structures were placed in $1 \mathrm{ml}$ of Medium $199+0.1 \%$ BSA and were frozen immediately. After freezing and thawing were repeated five times, the tissue samples were stored frozen until the renin assay was performed.

\section{Experimental protocols}

Time conirol. Afferent arterioles and arterioles with macula densa attached were incubated in Medium $199+0.1 \%$ BSA for two 30-min periods. Medium 199 had the following composition: $\mathrm{Na}^{+}, 133 \mathrm{meq} / \mathrm{liter} ; \mathrm{K}^{+}$, $5.4 \mathrm{meq} / \mathrm{liter} ; \mathrm{Cl}^{-}, 126 \mathrm{meq} / \mathrm{liter} ; \mathrm{Ca}^{2+}, 3.6 \mathrm{meq} / \mathrm{liter} ; \mathrm{HCO}_{3}^{-}, 14.9 \mathrm{mM}$; $\mathrm{H}_{2} \mathrm{PO}_{4}, 1.0 \mathrm{mM}$.

Adenosine. Afferent arterioles and arterioles with macula densa attached were incubated in Medium $199+0.1 \%$ BSA for the first (control) period and then placed in medium containing adenosine for the second (experimental) period. Two concentrations of adenosine were tested: 1.0 $\times 10^{-7} \mathrm{M}$ and $1.0 \times 10^{-5} \mathrm{M}$.

Synthetic adenosine receptor agonists. Since adenosine affected renin release only from afferent arterioles alone (see Results), this experiment was done using afferent arterioles alone. Arterioles were exposed to $N^{6}$ cyclohexyl adenosine (an $A_{1}$ adenosine receptor agonist [13]) or $5^{\prime}-\mathrm{N}$ ethylcarboxamide adenosine (an $A_{2}$ adenosine receptor agonist [13]) during the experimental period. Two concentrations of each agonist were tested: $1.0 \times 10^{-7} \mathrm{M}$ and $1.0 \times 10^{-5} \mathrm{M}$.

Antagonism of exogenous adenosine with theophylline. This experiment was carried out using afferent arterioles alone for the same reason as mentioned above. Afferent arterioles were pretreated with theophylline at $1.0 \times 10^{-5} \mathrm{M}$. It has been shown that this concentration of theophylline does not block phosphodiesterase but does block adenosine receptors (14). Theophylline was present from the preincubation to the end of incubations. Adenosine $\left(1.0 \times 10^{-7} \mathrm{M}\right)$ was added to the incubation medium for the second incubation period.

Antagonism of endogenous adenosine with theophylline. Since basal renin release was less in the presence of attached macula densa (see Results), we tested whether endogenous adenosine is involved in the inhibitory action of the macula densa. Afferent arterioles and arterioles with macula densa attached were exposed to the theophylline at 1.0 $\times 10^{-5} \mathrm{M}$ during the second incubation period.

\section{Analysis of renin activity}

Incubation medium and tissue samples were incubated with partially purified rabbit substrate equivalent to $1,000 \mathrm{ng}$ of angiotensin I (AI) ${ }^{1}$ at $37^{\circ} \mathrm{C}$ for $3 \mathrm{~h}$ (pH 6.5). Generated AI was measured by radioimmunoassay. Substrate was prepared by ammonium sulfate fractionation of the plasma obtained from 48-h nephrectomized rabbits. Substrate had specific activities ranging from 300 to $700 \mathrm{ng} \mathrm{AI} / \mathrm{mg}$ protein and had no detectable renin or angiotensinase activity.

1. Abbreviations used in this paper: Af, afferent arterioles; Af + MD, afferent arterioles with macula densa; AI, angiotensin I.
Renin release rate was calculated as nanograms of $\mathrm{Al}$ generated per hour per arteriole (Af) (or arteriole with macula densa [Af + MD]) per hour incubation of arteriole (or arteriole with macula densa) and expressed as $\mathrm{ng} \mathrm{AI} \cdot \mathrm{h}^{-1} \cdot \mathrm{Af}^{-1}$ (or $\mathrm{Af}+\mathrm{MD}^{-1}$ )/h. Tissue renin content of a single arteriole (or an arteriole with macula densa) was calculated and expressed as $\mathrm{ng} \mathrm{AI} \cdot \mathrm{h}^{-1} / \mathrm{Af}$ (or Af + MD).

All data were expressed as mean \pm SEM. Student's paired and unpaired $t$ tests were used for the statistical evaluation. A $P<0.05$ was considered to be significant.

\section{Results}

Time control. Renin release rates from afferent arterioles and afferent arterioles with macula densa attached were initially $0.69 \pm 0.09 \mathrm{ng} \mathrm{AI} \cdot \mathrm{h}^{-1} \cdot \mathrm{Af}^{-1} / \mathrm{h}$ and $0.20 \pm 0.04 \mathrm{ng} \mathrm{AI} \cdot \mathrm{h}^{-1} \cdot \mathrm{Af}$ $+\mathrm{MD}^{-1} / \mathrm{h}$, respectively, and they remained stable for $60 \mathrm{~min}$ (Table I). Although tissue renin content of afferent arterioles with macula densa attached was not different from that of afferent arterioles alone, renin release rate was significantly less in afferent arterioles with macula densa attached $(P<0.025)$. Thus, the ratio of renin release to tissue renin content was significantly smaller $(P<0.0005)$ in afferent arterioles with macula densa $(0.25 \pm 0.05 \%)$ than in afferent arterioles alone $(1.67 \pm 0.32 \%)$.

Adenosine. When afferent arterioles alone were exposed to adenosine at $1.0 \times 10^{-7} \mathrm{M}$, renin release rate decreased significantly from $0.72 \pm 0.16$ to $0.24 \pm 0.04 \mathrm{ng} \mathrm{AI} \cdot \mathrm{h}^{-1} \cdot \mathrm{Af}^{-1} / \mathrm{h}(P$ $<0.025$ ). However, exposure to $1.0 \times 10^{-5} \mathrm{M}$ adenosine did not result in a significant change in renin release from afferent arterioles alone (Table I). Renin release rate from afferent arterioles with macula densa attached was not significantly changed by exposure to adenosine either at $10^{-5} \mathrm{M}$ or at $10^{-7} \mathrm{M}$ (Table I).

Synthetic adenosine receptor agonists. When afferent arterioles alone were exposed to $N^{6}$-cyclohexyl adenosine at 1.0 $\times 10^{-7} \mathrm{M}$, renin release rate decreased significantly from $0.69 \pm 0.14$ to $0.39 \pm 0.12 \mathrm{ng} \mathrm{AI} \cdot \mathrm{h}^{-1} \cdot \mathrm{Af}^{-1} / \mathrm{h}(P<0.05)$ (Table II). However, renin release was not significantly altered by exposure to $N^{6}$-cyclohexyl adenosine at $1.0 \times 10^{-5} \mathrm{M}$. $5^{\prime}-N$-ethylcarboxamide adenosine either at $10^{-5} \mathrm{M}$ or $10^{-7} \mathrm{M}$ did not significantly change renin release (Table II).

Antagonism of exogenous adenosine with theophylline. Pretreatment with theophylline $\left(1.0 \times 10^{-5} \mathrm{M}\right)$ did not affect the basal renin release rate from afferent arterioles $(0.56 \pm 0.13$ and $0.65 \pm 0.12 \mathrm{ng} \mathrm{AI} \cdot \mathrm{h}^{-1} \cdot \mathrm{Af}^{-1} / \mathrm{h}$ in the first and second incubation periods, respectively). However, it prevented the decrease in renin release induced by adenosine at $1.0 \times 10^{-7} \mathrm{M}$ (Fig. 2).

Antagonism of endogenous adenosine with theophylline. When afferent arterioles alone were exposed to theophylline at $1.0 \times 10^{-5} \mathrm{M}$, renin release did not change significantly $\left(0.64 \pm 0.09\right.$ and $0.57 \pm 0.11 \mathrm{ng} \mathrm{AI} \cdot \mathrm{h}^{-1} \cdot \mathrm{Af}^{-1} / \mathrm{h}$ in control and experimental periods, respectively). However, when afferent arterioles with macula densa attached were exposed to the same concentration of theophylline, renin release increased signifcantly from $0.21 \pm 0.03$ to $0.46 \pm 0.08 \mathrm{ng} \mathrm{AI} \cdot \mathrm{h}^{-1} \cdot \mathrm{Af}+\mathrm{MD}^{-1} / \mathrm{h}$ $(P<0.05$, Fig. 3).

\section{Discussion}

We have previously been shown that microdissected afferent arterioles alone and afferent arterioles with macula densa attached can be used to study renin release $(11,12)$. These two 
Table I. Effect of Adenosine on Renin Release from Afferent Arterioles with and without Attached Macula Densa

\begin{tabular}{|c|c|c|c|c|}
\hline \multirow[b]{2}{*}{ Group } & \multirow[b]{2}{*}{ No. } & \multicolumn{2}{|l|}{ Renin release rate } & \multirow[b]{2}{*}{ Tissue renin content } \\
\hline & & I & II & \\
\hline & & $n g A I \cdot h^{-1} \cdot A f^{-1}\left(\right.$ or $\left.A f+M D^{-1}\right) / h$ & $n g A I \cdot h^{-1} \cdot A f^{-1}\left(\right.$ or $\left.A f+M D^{-1}\right) / h$ & $n g A I \cdot h^{-1} / A f($ or $A f+M d)$ \\
\hline \multicolumn{5}{|l|}{ Afferent arterioles } \\
\hline Time control & 16 & $0.69 \pm 0.09$ & $0.67 \pm 0.12$ & $62.6 \pm 12.2$ \\
\hline \multicolumn{5}{|l|}{ Adenosine } \\
\hline $1.0 \times 10^{-5} \mathrm{M}$ & 7 & $0.60 \pm 0.13$ & $0.62 \pm 0.17$ & $62.4 \pm 11.7$ \\
\hline $1.0 \times 10^{-7} \mathrm{M}$ & 9 & $0.72 \pm 0.16$ & $0.24 \pm 0.04^{*}$ & $40.2 \pm 7.3$ \\
\hline \multicolumn{5}{|c|}{$\begin{array}{c}\text { Afferent arterioles with } \\
\text { macula densa }\end{array}$} \\
\hline Time control & 6 & $0.20 \pm 0.04 \ddagger$ & $0.21 \pm 0.03 \ddagger$ & $91.5 \pm 21.2$ \\
\hline \multicolumn{5}{|l|}{ Adenosine } \\
\hline $1.0 \times 10^{-5} \mathrm{M}$ & 5 & $0.23 \pm 0.05 \S$ & $0.24 \pm 0.09 \S$ & $82.5 \pm 22.5$ \\
\hline $1.0 \times 10^{-7} \mathrm{M}$ & 5 & $0.30 \pm 0.08 \S$ & $0.27 \pm 0.03$ & $56.0 \pm 10.9$ \\
\hline
\end{tabular}

Microdissected afferent arterioles alone and arterioles with macula densa attached were incubated in Medium 199 during the first incubation period (I), and then exposed to adenosine during the second incubation period (II). Values are mean \pm SEM; No. refers to number of experiments. *, $P<0.025$ compared with control period (I); $\ddagger, P<0.025$ compared to afferent arterioles alone; $\S, P<0.05$.

preparations allow us to study renin release in the absence of glomeruli, tubules, and macula densa; and to study the influence of an attached macula densa on renin responses to various stimuli. Using these preparations, the present study was undertaken to examine the effects on renin release of exogenously administered adenosine and adenosine analogues; and to examine whether adenosine is involved in macula densa-mediated renin release. The results are consistent with the hypotheses that $(a)$ adenosine decreases renin release through the activation of $A_{1}$ adenosine receptors, and $(b)$ the macula densa may produce adenosine, which transmits an inhibitory signal to the juxtaglomerular cells.

We have previously reported that, in rabbits fed a normal sodium diet, basal renin release rate from afferent arterioles with attached macula densa $\left(0.25 \pm 0.03 \mathrm{ng} \mathrm{AI} \cdot \mathrm{h}^{-1} \cdot \mathrm{Af}+\mathrm{MD}^{-1} / \mathrm{h}\right)$ was significantly lower than that from afferent arterioles alone $\left(0.69 \pm 0.13 \mathrm{ng} \mathrm{AI} \cdot \mathrm{h}^{-1} \cdot \mathrm{Af}^{-1} / \mathrm{h}\right)(12)$. We speculated that this inhibitory effect of the macula densa on renin release may be due to the relatively high sodium chloride concentration of the incubation medium as compared with in vivo early distal tubular urine. Although sodium depleted rabbits were used in the present study, basal renin release rates both from afferent arterioles with macula densa $\left(0.20 \pm 0.04 \mathrm{ng} \mathrm{AI} \cdot \mathrm{h}^{-1} \cdot \mathrm{Af}+\mathrm{MD}^{-1} / \mathrm{h}\right)$ and from afferent arterioles alone $\left(0.69 \pm 0.09 \mathrm{ng} \mathrm{AI} \cdot \mathrm{h}^{-1} \cdot \mathrm{Af}^{-1} / \mathrm{h}\right)$ were similar to those in our previous study in which normal sodium diets were used (12). Thus, we have confirmed our earlier observation that sodium depletion does not affect renin release from microdissected afferent arterioles (11). In addition, these data show that the inhibitory action of the attached macula densa on renin release is not altered by previous sodium depletion of rabbits. These observations are in contrast with previous reports that sodium depletion increases renin release (15-17), possibly through a macula densa-mediated mechanism $(7,18)$. The difference between our present results and those of others may be due to the unique characteristics of the present preparations. First, our preparations have no interlobular arteries or efferent

Table II. Effect of Adenosine Receptor Agonists on Renin Release from Microdissected Afferent Arterioles

\begin{tabular}{|c|c|c|c|c|}
\hline \multirow[b]{2}{*}{ Group } & \multirow[b]{2}{*}{ No. } & \multicolumn{2}{|l|}{ Renin release rate } & \multirow[b]{2}{*}{ Tissue renin content } \\
\hline & & $\mathbf{I}$ & II & \\
\hline & & $n g A I \cdot h^{-1} \cdot A f^{-1} / h$ & $n g A I \cdot h^{-1} \cdot A f^{-1} / h$ & $n g A I \cdot h^{-1} / A f$ \\
\hline \multicolumn{5}{|c|}{$\mathrm{N}^{6}$-cyclohexyl adenosine } \\
\hline $1.0 \times 10^{-5} \mathrm{M}$ & 7 & $0.61 \pm 0.14$ & $0.56 \pm 0.17$ & $46.7 \pm 11.4$ \\
\hline $1.0 \times 10^{-7} \mathrm{M}$ & 5 & $0.69 \pm 0.14$ & $0.39 \pm 0.12^{*}$ & $52.5 \pm 23.4$ \\
\hline \multicolumn{5}{|c|}{$5^{\prime}-N$-ethylcarboxamide adenosine } \\
\hline $1.0 \times 10^{-5} \mathrm{M}$ & 9 & $0.48 \pm 0.18$ & $0.62 \pm 0.14$ & $63.5 \pm 11.8$ \\
\hline $1.0 \times 10^{-7} \mathrm{M}$ & 7 & $0.49 \pm 0.19$ & $0.56 \pm 0.24$ & $41.2 \pm 8.87$ \\
\hline
\end{tabular}

Microdissected afferent arterioles alone were incubated in Medium $199+0.1 \%$ BSA during the first incubation period (I) and then exposed during the second period (II) to either $N^{6}$-cyclohexyl adenosine ( $\mathrm{A}_{1}$ adenosine receptor agonist) or $5^{\prime}-N$-ethylcarboxamide adenosine $\left(\mathrm{A}_{2}\right.$ adenosine receptor agonist). Values are mean \pm SEM. "No." refers to number of experiments. ${ }^{*}, P<0.05$ compared with control period (I). 


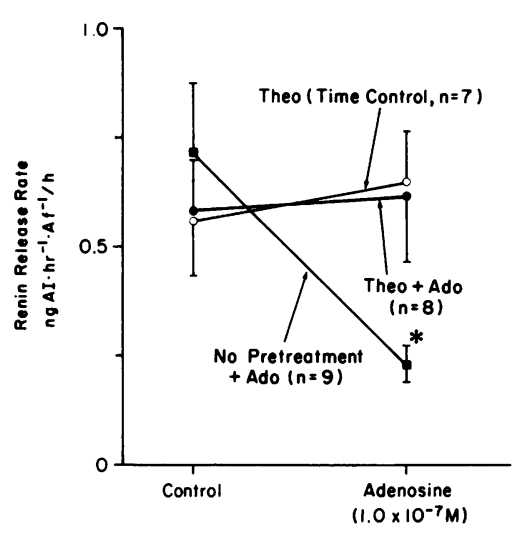

Figure 2. Effect of the pretreatment with theophylline on adenosineinduced decrease in renin release from microdissected afferent arterioles of rabbit kidneys. Theophylline (Theo) at $1.0 \times 10^{-5} \mathrm{M}$ was present from the preincubation to the end of incubations (open and closed circles). Afferent arterioles were exposed to adenosine (Ado) at 1.0 $\times 10^{-7} \mathrm{M}$ during second incubation period (closed symbols). ${ }^{*}, P$ $<0.025$ compared with control period.

arterioles, which may contribute to the increase in renin release seen during sodium depletion in other studies. Second, since tubular segments continuous with the macula densa are very short in our preparation of afferent arterioles with macula densa, it is unlikely that tubular transport would significantly reduce the concentration of sodium chloride reaching the macula densa; therefore, sodium chloride concentration at the macula densa in our preparation would closely reflect medium sodium chloride concentration and would be much higher than that in vivo. Thus, even if the macula densa provided a stimulatory effect on renin release during sodium depletion in vivo, it may supress renin release in our present preparation.

Adenosine at $1.0 \times 10^{-7} \mathrm{M}$ presently decreased renin release from afferent arterioles alone; however, it did not alter renin release from afferent arterioles with macula densa attached. This result suggests that the macula densa may produce a significant amount of adenosine, possibly in response to the high sodium chloride concentration of the incubation medium (and, thus,

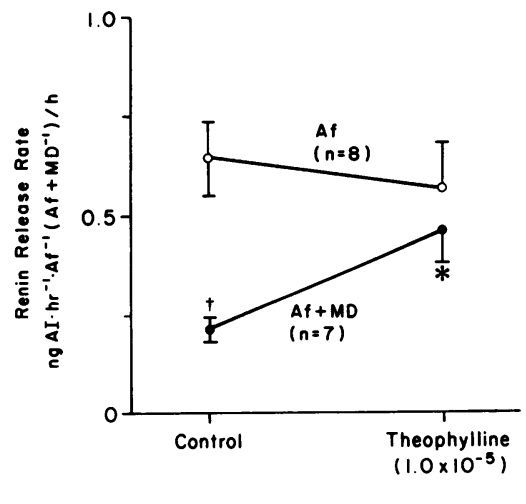

Incubation Period

Figure 3. Effect of theophylline on renin release from afferent arterioles alone ( $(0)$ and afferent arterioles with attached macula densa ( $\bullet$ ). ${ }^{*}, P<0.05$ compared with control period. $\dagger, P<0.05$ compared with afferent arterioles alone. Af, afferent arterioles; Af $+M D$, afferent arterioles with attached macula densa. high sodium chloride concentration at the macula densa). This endogenously produced adenosine could inhibit renin release, leading to a significantly lower basal renin release rate in afferent arterioles with macula densa attached than in afferent arterioles alone. Then, a further increase in adenosine levels by the exogenous administration of adenosine would not have any additional effect on renin release from afferent arterioles with macula densa attached. This could be compatible with previous reports that adenosine decreases renin release in sodium-depleted animals (1-3), but not in sodium-loaded animals $(2,3)$. These in vivo observations $(2,3)$ could also be interpreted in the same way; that is to say, if endogenous levels of adenosine were already high in sodium loaded animals, then exogenous adenosine could not further inhibit renin release.

To examine whether adenosine is involved in the inhibitory action of attached macula densa on basal renin release, we exposed afferent arterioles alone and afferent arterioles with attached macula densa to theophylline at $1.0 \times 10^{-5} \mathrm{M}$. As shown in this study, this concentration of theophylline antagonized the inhibitory effect of adenosine on renin release. Theophylline increased renin release only in the presence of attached macula densa. During exposure to theophylline, the renin release rate from afferent arterioles with macula densa attached was no longer different than that from afferent arterioles alone. This result is in concert with the finding that exogenous adenosine inhibited renin release only in the absence of attached macula densa. These two observations support the hypothesis that the macula densa may produce adenosine, which inhibits renin release.

It could be argued, however, that actions of theophylline other than the antagonism of adenosine receptors participated in the renin responses observed in this study. In addition to its being an adenosine receptor antagonist, theophylline is a wellknown inhibitor of phosphodiesterase (19). However, the concentration of theophylline employed in the present study (1.0 $\times 10^{-5} \mathrm{M}$ ) is reported to have no effect on the tissue levels of cyclic AMP in rabbit (5) and dog (20) kidneys. Much higher concentrations of theophylline (millimolar range) are required to increase tissue levels of cyclic $\operatorname{AMP}(5,14,20)$. This suggests that the renin response to theophylline in the present study was not due to phosphodiesterase inhibition; rather, it could have been due to antagonism of adenosine receptors.

It has now been recognized that there are at least two classes of extracellular receptors involved in the action of adenosine, namely $A_{1}$ and $A_{2}$ adenosine receptors (13). $A_{1}$ adenosine receptors have a high affinity for adenosine and in some cells couple to adenylate cyclase in an inhibitory manner $(21,22) . A_{2}$ adenosine receptors have a lower affinity for adenosine and in many cell types couple to adenylate cyclase in a stimulatory manner $(21,23,24)$. Using an isolated-perfused rat kidney preparation, Murray and Churchill $(25,26)$ showed that $N^{6}$-cyclohexyl adenosine decreases renin secretory rate in a concentration-dependent manner and suggested that the decrease was due to activation of $\mathrm{A}_{1}$ adenosine receptors; 5'- $N$-ethylcarboxamide adenosine, on the other hand, stimulated renin secretion in a concentrationdependent manner, suggesting that $\mathrm{A}_{2}$ adenosine receptor agonism is associated with increases in renin secretion. Both adnosine and $N^{6}$-cyclohexyl adenosine at $1.0 \times 10^{-7} \mathrm{M}$ decreased renin release in the present study. However, at the higher concentration $\left(1.0 \times 10^{-5} \mathrm{M}\right)$, they did not alter renin release rate. This observation may be compatible with the hypothesis that juxtaglomerular cells have both $A_{1}$ and $A_{2}$ receptors $(25,26)$ 
and that changes in intracellular cyclic AMP levels mediate the adenosine-induced renin release. In other words, low concentrations of adenosine and $N^{6}$-cyclohexyl adenosine could have decreased the intracellular levels of cyclic AMP via the selective activation of $A_{1}$ adenosine receptors and thus decreased renin release. On the other hand, a high concentration of these compounds (for example, $10^{-5} \mathrm{M}$ adenosine or $N^{6}$-cyclohexyl adenosine in the present experiments) could have nonselectively activated both $A_{1}$ and $A_{2}$ adenosine receptors resulting in no net change in either cyclic AMP or renin secretion.

5 - $N$-ethylcarboxamide adenosine is a potent analogue of $\mathrm{A}_{2}$ adenosine receptors (13); and, it has been reported that this compound at concentrations of $1.0 \mu \mathrm{M}$ or greater increases renin release in the isolated-perfused rat kidney $(25,26)$. The reason for the failure of $5^{\prime}-N$-ethylcarboxamide adenosine to increase renin secretion in the present study is not known, but may be due to the difference in species (rabbits vs. rats) or the difference in the experimental preparations (isolated afferent arterioles vs. isolated-perfused kidneys). Alternatively, since 5 '- $N$-ethylcarboxamide adenosine is not specific for $\mathrm{A}_{2}$ receptors, it may activate $A_{1}$ as well as $A_{2}$ receptors, resulting in no net change in renin release.

In summary, the present results are consistent with an effect of adenosine to decrease renin release which is independent of changes in hemodynamics, sodium excretion, or sympathetic nervous activity. This inhibitory action of adenosine on renin release may be mediated by the activation of $A_{1}$ adenosine receptors. The results are also consistent with the hypothesis that the macula densa may produce adenosine, which could be a transmitter of an inhibitory signal from the macula densa to juxtaglomerular cells. However, further experiments will be necessary to test this hypothesis both in vivo and in vitro.

\section{Acknowledgments}

We gratefully acknowledge the assistance of Dr. L. Barajas in the interpretation of the electromicrograph (Fig. 1).

This study was supported in part by National Institutes of Health grant HL-28982.

\section{References}

1. Tagawa, H., and A. J. Vander. 1970. Effects of adenosine compounds on renal function and renin secretion in dogs. Circ. Res. 26: 327-338.

2. Osswald, H., H. J. Schmitz, and R. Kemper. 1978. Renal action of adenosine: effect on renin secretion in the rat. Naunyn-Schmiedeberg's Arch. Pharmacol. 303:95-99.

3. Osswald, H., H. J. Schmitz, and O. Heidenreich. 1975. Adenosine response of the rat kidney after saline loading, sodium restriction and hemorrhagia. Pfluegers Arch. Eur. J. Physiol. 357:323-333.

4. Osswald, H., W. S. Spielman, and F. G. Knox. 1978. Mechanism of adenosine-mediated decreases in glomerular filtration rate in dogs. Circ. Res. 43:465-469.

5. Hedqvist, P., B. Fredholm, and S. Olundh. 1978. Antagonistic effects of theophylline and adenosine on adrenergic neuroeffector transmission in the rabbit kidney. Circ. Res. 43:592-598.

6. Barchowsky, A., J. L. Data, and A. R. Whorton. 1984. The demonstration of an inhibitory adenosine receptor controlling the release of renin. Fed. Proc. 43:366.

7. Vander, A. J. 1967. Control of renin release. Physiol. Rev. 47: 359-382.

8. Osswald, H., G. Nabakowski, and H. Hermes. 1980. Adenosine as a possible mediator of metabolic control of glomerular filtration rate. Int. J. Biochem. 12:263-267.

9. Spielman, W. S., and C. I. Thompson. 1982. A proposed role for adenosine in the regulation of renal hemodynamics and renin release. Am. J. Physiol. 242:F423-F435.

10. Osswald, H. 1984. The role of adenosine in the regulation of glomerular filtration rate and renin secretion. Trends Pharmacol. Sci. 5: 94-97.

11. Itoh, S., O. A. Carretero, and R. D. Murray. 1985. Renin release from isolated afferent arterioles. Kidney Int. 27:762-767.

12. Itoh, S., and O. A. Carretero. 1985. Role of macula densa in renin release. Hypertension 7:49-54.

13. Daly, J. W. 1982. Adenosine receptors: targets for future drugs. J. Med. Chem. 25:197-207.

14. Bruns, R. F. 1981. Adenosine antagonism by purines, pteridines, and benzopteridines in human fibroblasts. Biochem. Pharmacol. 30:325333.

15. Braverman, B., R. H. Freeman, and H. H. Rostorfer. 1971. The influence of dietary sodium chloride on in vitro renin release from rat kidney slices. Proc. Soc. Exp. Biol. Med. 138:81-88.

16. Park, C. S., R. L. Malvin, R. D. Murray, and K. W. Cho. 1978. Renin secretion as a function of renal renin content in dogs. Am. J. Physiol. 234:F506-F509.

17. Brown, J. J., D. L. Davies, A. F. Lever, and J. I. S. Robertson. 1963. Influence of sodium loading and sodium depletion in man. Lancet. I:278-279.

18. Churchill, P. C., M. C. Churchill, and F. D. McDonald. 1978. Renin secretion and distal tubule $\mathrm{Na}^{+}$in rats. Am. J. Physiol. 235:F611F616.

19. Robinson, G. A., R. W. Butcher, and E. W. Sutherland. 1971. Cyclic AMP. Academic Press, London. 1-531.

20. Spielman, W. S. 1984. Antagonistic effect of theophylline on the adenosine-induced decrease in renin release. Am. J. Physiol. 247:F246F251.

21. Londos, C., D. M. F. Cooper, and J. Wolff. 1980. Subclasses of external adenosine receptors. Proc. Natl. Acad. Sci. USA. 77:2551-2554.

22. Van Calker, D., M. Muller, and B. Hampercht. 1978. Adenosine inhibits the accumulation of cyclic AMP in cultured brain cells. Nature (Lond.). 276:839-841.

23. Woodcock, E. A., R. Loxley, E. Leung, and C. I. Johnston. 1984. Demonstration of $\mathbf{R}_{\mathrm{A}}$-adenosine receptors in rat renal papillae. Biochem. Biophys. Res. Commun. 121:434-440.

24. Bruns, R. F. 1980. Adenosine receptor activation in human fibroblasts: nucleoside agonists and antagonists. Can. J. Physiol. Pharmacol. 58:673-691.

25. Murray, R. D., and P. C. Churchill. 1984. Effects of adenosine receptor agonists in the isolated, perfused rat kidney. Am. J. Physiol. 247:H343-H348.

26. Murray, R. D., and P. C. Churchill. 1985. Concentration dependency of the renal vascular and renin secretory responses to adenosine receptor agonists. J. Pharmacol. Exp. Ther. 232:189-193. 